\title{
ARTICLE
}

\section{Temporal variation of the pseudo total content of heavy metals in Ulaanbaatar soil}

\author{
Tsagaan Byambasuren*, Byambaa Khuukhenkhuu, Ganbaatar Ochirbat and Darizav Tsedenbaljir
}

Institute of Physics and Technology, Mongolian Academy of Sciences Ulaanbaatar, Mongolia

ARTICLE INFO: Received: 8 Aug, 2019; Accepted: 9 Dec, 2019

\begin{abstract}
This work shows some of the results of investigation into pseudo total content of heavy metals in the surface soil of Ulaanbaatar.

The main objectives of this study are to (i) evaluate temporal variability of pseudo-total content of $\mathrm{Pb}, \mathrm{Cu}$, $\mathrm{Zn}, \mathrm{Cd}, \mathrm{Cr}, \mathrm{Ni}$, Co and Mn in surface soil of Ulaanbaatar collected from 2003 to 2018, (ii) identify the main discriminates - metals during the years 2003-2018 years and, (iii) investigate the interdependence of main discriminates on the soil reaction $(\mathrm{pH})$ and soil organic matter.

Due to urbanization and negative human activities, surface soil in Ulaanbaatar losing their natural features, which are changing, while the spatial and temporal distribution of heavy metals in urban surface soil is becoming irregular. In Ulaanbaatar surface soil, the mean concentration of $\mathrm{Cu}, \mathrm{Zn}$ and $\mathrm{Pb}$ much mois very high and the mean concentration of Co is lower than background soil. In some land use zones, it was found that the mean concentraion of $\mathrm{Zn}$ and $\mathrm{Cr}$ was considerably higher than the permissible level. The pollution condition of $\mathrm{Mn}, \mathrm{Zn}, \mathrm{Cr}, \mathrm{Ni}$ and $\mathrm{Cd}$ was the same in 2010-2018 and the pollution conditions of $\mathrm{Pb}, \mathrm{Cu}$ and $\mathrm{Co}$ are different. The main discriminants are $\mathrm{Pb}, \mathrm{Cu}$ and $\mathrm{Co}$. In Ulaanbaatar soil, a strikingly close correlationhip was established for $\mathrm{Cu}, \mathrm{Pb}$ with the soil organic matter, and for $\mathrm{Cd}, \mathrm{Zn}, \mathrm{Cr}$ with the $p H$, respectively.
\end{abstract}

Keywords: Ulaanbaatar; surface soil; temporal variation; heavy metal pollution; discrimination analysis; factor and cluster analysis;

\section{INTRODUCTION}

Rapid urbanization, expansion of the industrial sector, and increasing vehicle emissions have largely led to heavy metal contamination of urban soils. Heavy metal contamination of urban soils, due to their toxicity and close relationship with the humans, continue to cause grave concern of the public, as well as international environmentalists.

Two principal sources - anthropogenic and lithogenic, have been recognized for typical enrichment of heavy metals in urban soils [15].

In recent years, similarly like in any other major city, the state of ecological environment in Ulaanbaatar has been seriously compromised by urbanization and population growth. 
The soil cover has changed significantly and soil is polluted with heavy metals. Numerous studies have been carried out on heavy metal contamination of Ulaanbaatar soil. In our previous studies. we focused on spatial distribution pattern, source identification and the degree of pollution [6-14]. The toxicity of heavy metals depends on their forms or species in the soil and soil properties [3-4]. For the soils of Ulaanbaatar there are only few scientific works devoted to the study of their forms in soil $[10,15]$.

Pseudo-total concentration of heavy metals is expressed through the content of elements, which is measured in a soil sample after

\section{MATERIALS AND METHODS}

Object: Surface soil samples collected in 2003 (410), 2010 (57), 2014 (117) and 2018 (215) respectively are the main objects of this study. Urban soils were taken at a depth of $0-10 \mathrm{~cm}$ from the soil surface by "envelope" method on irregular network [16, 17]. Soil samples were dried at room temperature in air-dry condition and large inclusions, such as stones, glass, and plant roots were removed, sieved and ground in the Fritsch instrument.

Chemical analysis: The pseudo-total content of heavy metals in surface soil was exctacted in a mixture of $\mathrm{HNO}_{3}+\mathrm{O}_{2}$ acid [18]. All measurements were performed using the Perkin-Elmer Model 5000 and Shimadzu $6300 \mathrm{C}$ atomic absorption spectrophotometer with flame atomization (FAAS). Air-acetylene flame and standard calibration methods were applied for atomization and determination of the pseudo-total content of heavy metals.

\section{RESULTS AND DISCUSSIONS}

Soil properties: Soil pollution (especially high-level) with compounds of heavy metals leads to a change in the chemical, physical and biological properties of the soil. The results of the reaction $(\mathrm{pH})$ and organic matter $(\mathrm{OM})$ of the surface soil are presented in Table1. incomplete acid decomposition and is used for assessing potential risk and is also useful for assessing the direct intake of soil metals by young children or animals [4].

The main objectives of this study are to (i) evaluate temporal variability of pseudo-total content of $\mathrm{Pb}, \mathrm{Cu}, \mathrm{Zn}, \mathrm{Cd}, \mathrm{Cr}, \mathrm{Ni}, \mathrm{Co}$ and $\mathrm{Mn}$ in surface soil of Ulaanbaatar collected from 2003 to 2018 , (ii) identify the main discriminates metals during the years 2003-2018 years and, (iii) investigate the interdependence of main discriminates on the soil reaction $(\mathrm{pH})$ and soil organic matter. And herein lies the novelty of our work.

Quality control of the results was carried out using the analysis of certified standard reference samples SP-3, SP-2, SP-3. We determined the $\mathrm{pH}$ value of the soil water extracts using the potentiometric method and soil organic matter by ignition [19].

Statistical analysis: A Kruskal-Wallis rank ANOVA test and median test were used for the comparison of quantitative variables between 2003 and 2018. Discrimination analysis was used for the study of temporal variation of elements in soil and identification of respective discriminative variables for each years. Using CA and FA, elements with similar geochemical behavior and the dependence of the behavior of HM in soil on $\mathrm{pH}$ and SOM were identified.

Statistical procedures were calculated and generalized with Microsoft Office Excel 2013 and Statistica 13.

According to our result (Table 1.), it was found that the $\mathrm{pH}_{(\mathrm{H} 2 \mathrm{O})}$ in surface soil varies from slightly acidic (5.62) to alkaline (8.97), $\mathrm{pH}_{(\mathrm{H} 2 \mathrm{O})}$ average value is a neutral and slightly alkaline. As some authors have noted, urban soils are characterized by changes in $\mathrm{pH}$ values towards 
alkalization, which is also confirmed by our studies. Alkalization of soils shows that the soil cover of Ulaanbaatar is contaminated in some

Table 1. Statistical results of soil organic matter (SOM, \%) and $\mathrm{pH}$

\begin{tabular}{|c|c|c|c|c|c|c|c|}
\hline & BG & Max & Mean & Median & Min & $\sigma$ & V, \% \\
\hline $\mathrm{SOM}$ & 7.95 & 36.39 & 9.47 & 7.66 & 2.27 & 6.83 & 46.73 \\
\hline $\mathrm{pH}_{(\mathrm{H} 2 \mathrm{O})}$ & 6.61 & 8.97 & 7.45 & 7.52 & 5.62 & 0.47 & 0.22 \\
\hline
\end{tabular}

Organic matter in surface soils ranges from $2.27-36.39 \%$, averages $7.66 \%$ and is closer to the value of background soil (7.95). The high variability $(46.73 \%)$ of soil organic matter indicates anthropogenic pollution of soils at some points.

Concentration and distribution of heavy metals in Ulaanbaatar soil between 2003 and 2018. The concentration of heavy metals in Ulaanbaatar soil in the years 2003-2018, regional background value $\left(C_{B G}\right)$ for pseudo- places due to various sources of pollution, since the soil reaction $(\mathrm{pH})$ in the background soil was weakly acidic (6.61).

Table 2. Concentration of heavy metals in Ulaanbaatar soil in the years betweem 2003 and 2018, regional background value $\left(C_{B G}\right)$ for pseudo-total contents of elements in Ulaanbaatar surface soil and the maximum permissible concentrations (MPC - *Standard), extracted in $1 \mathrm{~N} \mathrm{HCl}$

\begin{tabular}{|c|c|c|c|c|c|c|c|c|c|}
\hline \multirow{2}{*}{ groups } & \multirow{2}{*}{$n$} & \multicolumn{8}{|c|}{ Concentration of heavy metals, $\mathrm{mg} / \mathrm{kg}$} \\
\hline & & Co & $M n$ & $Z n$ & $P b$ & $\mathrm{Cu}$ & $\mathrm{Cr}$ & $\mathrm{Ni}$ & $C d$ \\
\hline 2003 & 410 & 8.83 & - & - & 67.8 & 40.5 & - & 21.32 & 1.13 \\
\hline 2010 & 57 & 7.25 & 159 & 70.7 & 64.8 & 47.9 & 18.32 & 15.59 & 0.3 \\
\hline 2014 & 117 & 8.08 & 204 & 93.7 & 39.1 & 22.5 & 43.54 & 10.78 & 0.57 \\
\hline 2018 & 215 & 7.43 & 164 & 56.6 & 33.4 & 24.1 & 31.85 & 16.69 & 1.03 \\
\hline \multicolumn{2}{|c|}{$C_{B G}$} & 9.43 & 168 & 50.1 & 11.2 & 13.8 & 25.95 & 19.93 & 0.84 \\
\hline \multicolumn{2}{|c|}{ *Standard } & 12 & 600 & 60 & 60 & 50 & 15 & 36 & 1 \\
\hline \multirow{2}{*}{$\mathrm{K}-\mathrm{W}$} & $\mathrm{H}$ & 20.31 & 556.82 & 329.41 & 160.89 & 117.22 & 604.14 & 200.73 & 185.32 \\
\hline & $\mathrm{p}$ & 0.0001 & 0.0000 & 0.0000 & 0.0000 & 0.0000 & 0.0000 & 0.0000 & 0.0000 \\
\hline
\end{tabular}

The accumulation and leaching tendency for all investigated heavy metals are not identical during all the periods when the study was carried out. The distribution pattern of pseudo-total content of heavy elements in total contents of elements in Ulaanbaatar surface soil [20] and the maximum permissible concentrations (MPC -*standard), extracted in $1 \mathrm{~N} \mathrm{HCl}[21]$ are presented in Table 2 . The distribution of elements in Ulaanbaatar soil during 2003-2018 were tested by the K-W ANOVA test and are also presented in the Table. Further figure 1 (example) shows the distribution of $\mathrm{Co}$ and $\mathrm{Pb}$ in Ulaanbaatar soil during the years from 2003 to 2018. 

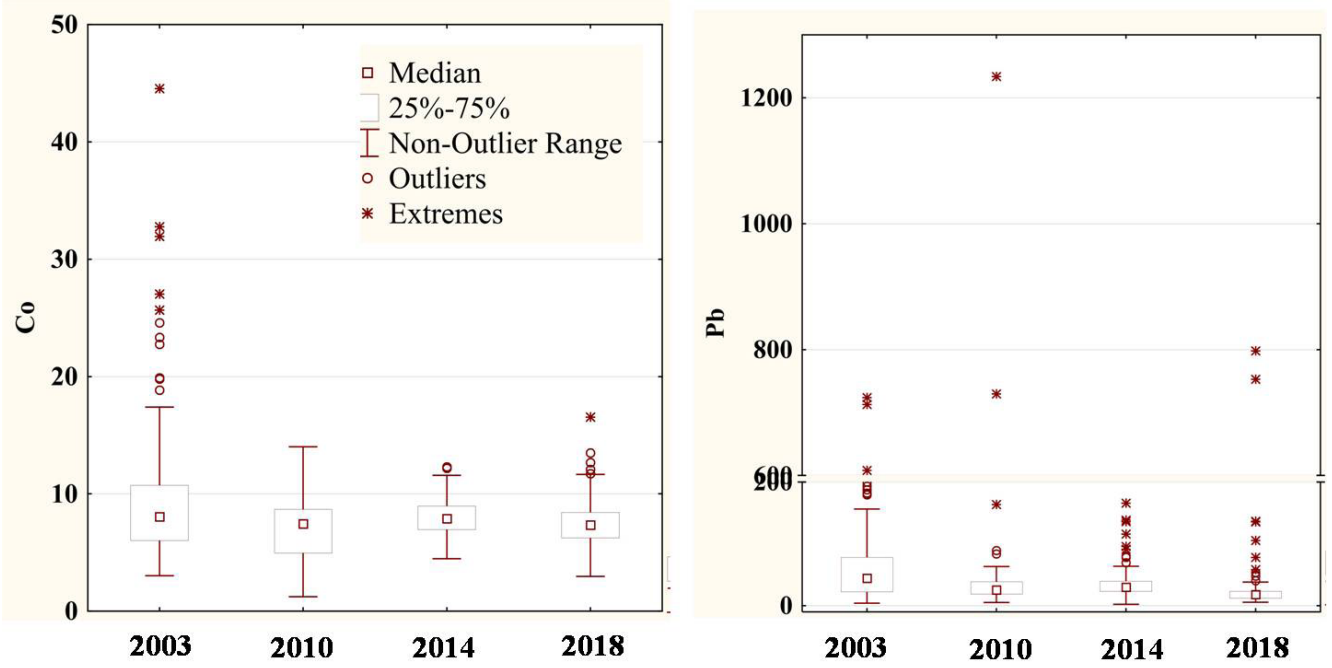

Figure 1. Distribution of pseudo-total concentration of $\mathrm{Co}$ and $\mathrm{Pb}$

As can be seen from Table 1, from 2003 to 2018 , excluding only 2014, the concentration for $\mathrm{Pb}, \mathrm{Cu}, \mathrm{Zn}$ decreases, which may indicate the positive outcome of the government's efforts to curb environmental pollution on the territory of Ulaanbaatar, such as restriction of number of vehicles on the road. On the other hand, the concentration for $\mathrm{Mn}, \mathrm{Co}, \mathrm{Ni}$, $\mathrm{Cd}$ increases, the biogeochemical feature of urban soil cover in Ulaanbaatar, since these pedogenic and lithogenic elements [20,21] are leached by human exposure. On the contrary, $\mathrm{Cr}$ showed different results.

In Mongolia, MPC standard for total contents of heavy metals have been approved and adopted, while the standards for pseudo-total concentration or acid-soluble concentration of HM have not been adopted. In order to assess the ecological state of soils by pseudo-total concentration or acid-soluble concentration of HM, we was the value of heavy metal concentration, extracted in $1 \mathrm{~N}$ $\mathrm{HCl}$, as in Russia. When comparing with value extracted in $1 \mathrm{~N} \mathrm{HCl}$, the pseudo-total concentration of only the $\mathrm{Cr}$ content in the background soil and $\mathrm{Zn}$ and $\mathrm{Cr}$ contents in urban soil are higher.

The results of this study were compared with the other findings of studies that werecarried out in 2008-2012 [15, 23-26]. Although the conditions and times, when the studies were carried out are different, the distribution feature and pollution status were the same and a high content was noted in the industrial and ger districts of the city.

\section{Temporal variation}

Temporal variation of heavy metals in Ulaanbaatar soil was estimated using multiple stepwise discriminate analyses to distinguish the main elements, which were being increasingly accumulated in the tears 20032018 and which were polluting the surface soil in Ulaanbaatar and the results of the study are summarized in Table 3. According to our analysis, the state of contamination is clearly distinguished with Co (Wilks' $\chi-0,194$ ) in the standard and forward stepwise mode $\mathrm{Cu}$ (Wilks' $\chi-0.192)$. In the backward stepwise mode, $\mathrm{Mn}$, $\mathrm{Zn}, \mathrm{Cr}, \mathrm{Ni}$, and $\mathrm{Cd}$ are included in the models and are the main elements indicating the geochemical features of the city's soils. This indicates that during 2010-2018, the ecological state of Ulaanbaatar soil was different in terms of the concentration of $\mathrm{Mn}, \mathrm{Zn}, \mathrm{Cr}, \mathrm{Ni}$, and $\mathrm{Cd}$ due to the biogeochemical feature of soil cover in the city. 
Table 3. Stepwise discrimination analysis result

\begin{tabular}{|c|c|c|c|c|c|c|c|c|c|c|c|c|}
\hline \multirow{3}{*}{$\frac{\bar{s}}{\tilde{z}}$} & \multicolumn{4}{|c|}{ Standard mode } & \multicolumn{4}{|c|}{ Forward stepwise mode } & \multicolumn{4}{|c|}{ Backward stepwise mode } \\
\hline & \multicolumn{4}{|c|}{$\begin{array}{c}\text { Wilks' } \chi: 0.19 ; \\
F(16,758)=60.72 ; p<0.0000\end{array}$} & \multicolumn{4}{|c|}{$\begin{array}{c}\text { Wilks' } \chi: 0.19 ; \\
F(14,760)=69.52 ; p<0.0000\end{array}$} & \multicolumn{4}{|c|}{$\begin{array}{c}\text { Wilks' } \chi: 0.19 ; \\
F(10,764)=94.62 ; p<0.0000\end{array}$} \\
\hline & $\begin{array}{l}\text { Wilks } \\
\chi\end{array}$ & $F$ & $p$ & $R^{2}$ & $\begin{array}{l}\text { Wilks } \\
\quad \chi\end{array}$ & $F$ & $p$ & $R^{2}$ & $\begin{array}{l}\text { Wilks } \\
\quad \chi\end{array}$ & $F$ & $p$ & $R^{2}$ \\
\hline Co & 0.194 & 2.157 & 0.117 & 0.751 & 0.194 & 2.135 & 0.120 & 0.754 & & & & \\
\hline$M n$ & 0.242 & 48.806 & 0.000 & 0.713 & 0.242 & 48.778 & 0.000 & 0.715 & 0.270 & 67.493 & 0.000 & 0.787 \\
\hline$Z n$ & 0.252 & 58.755 & 0.000 & 0.767 & 0.253 & 59.651 & 0.000 & 0.772 & 0.271 & 68.850 & 0.000 & 0.806 \\
\hline $\mathrm{Pb}$ & 0.196 & 4.001 & 0.019 & 0.577 & 0.197 & 5.030 & 0.007 & 0.905 & & & & \\
\hline $\mathrm{Cu}$ & 0.192 & 0.162 & 0.851 & 0.583 & & & & & & & & \\
\hline $\mathrm{Cr}$ & 0.203 & 11.214 & 0.000 & 0.975 & 0.204 & 11.322 & 0.000 & 0.976 & 0.210 & 10.230 & 0.000 & 0.985 \\
\hline$N i$ & 0.273 & 80.317 & 0.000 & 0.663 & 0.276 & 83.003 & 0.000 & 0.689 & 0.285 & 81.999 & 0.000 & 0.722 \\
\hline$C d$ & 0.389 & 194.340 & 0.000 & 0.800 & 0.391 & 196.279 & 0.000 & 0.805 & 0.399 & 190.834 & 0.000 & 0.823 \\
\hline
\end{tabular}

The relationship between heavy metals and basic soil properties

Many researchers have found that the accumulation and migration of elements in the soil is determined by the physicochemical properties of soils (physical clay, absorbed substrates, soil reaction and organic matter). Accumulation and migration dependence of heavy metals in the soil was investigated applying the factor and cluster analysis. The results are presented in Figure 2 and Table 4.

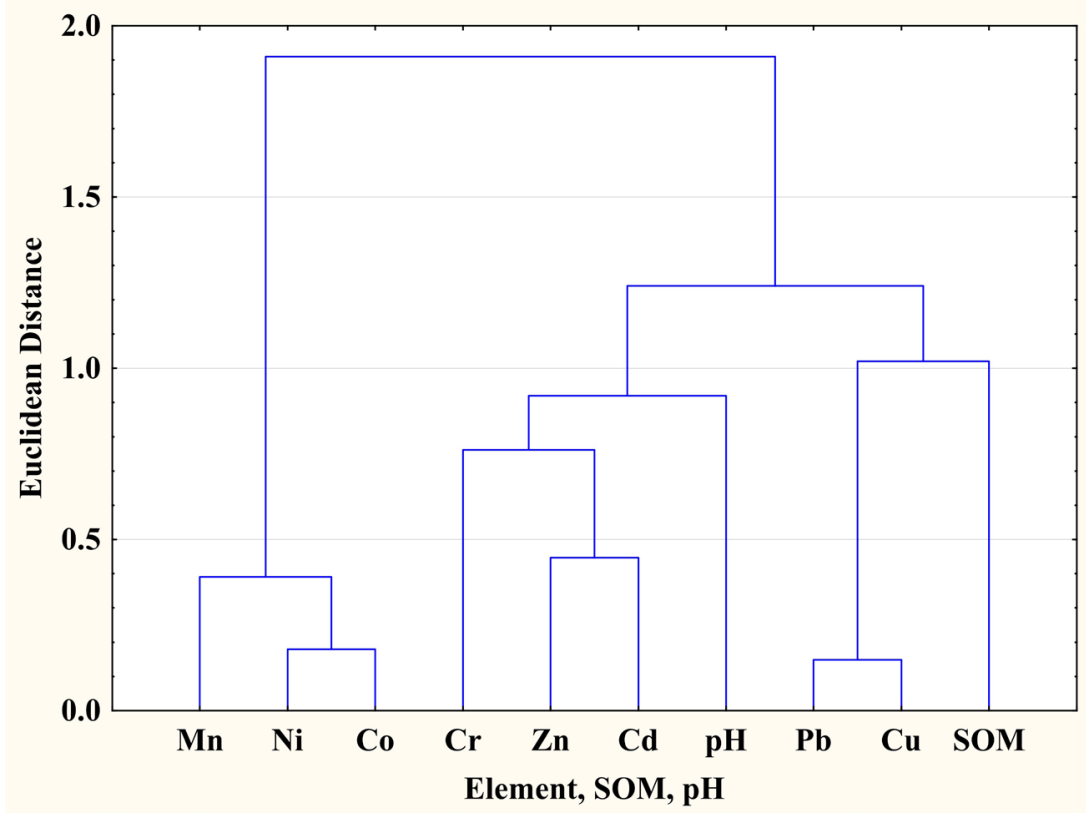

Figure 2. Dendogram of relationship between metals and SOM and pH in urban soils 
Table 4. Results of factor analysis showing relative loading of pseudo total concentration metals

(The loadings over 0.45 are marked in bold).

\begin{tabular}{|c|c|c|c|}
\hline Statistic & $P C-1$ & $P C-2$ & $P C-3$ \\
\hline Eigenvalue & 3.70 & 1.95 & 1.51 \\
\hline Variance, $\%$ & 36.96 & 19.51 & 15.06 \\
\hline Cumulative explained variance, \% & 36.96 & 56.46 & 71.53 \\
\hline Element & \multicolumn{3}{|c|}{ Loading } \\
\hline$P b$ & $\mathbf{0 . 9 1 8}$ & -0.163 & 0.107 \\
\hline$C u$ & $\mathbf{0 . 8 9 3}$ & 0.231 & 0.124 \\
\hline$C d$ & $\mathbf{0 . 6 8 3}$ & 0.403 & -0.092 \\
\hline$Z n$ & $\mathbf{0 . 5 4 9}$ & 0.409 & -0.203 \\
\hline$N i$ & 0.069 & $\mathbf{0 . 9 4 3}$ & 0.102 \\
\hline$C o$ & 0.006 & $\mathbf{0 . 8 4 0}$ & 0.279 \\
\hline$M n$ & 0.306 & $\mathbf{0 . 7 2 5}$ & 0.205 \\
\hline$C r$ & 0.159 & 0.493 & -0.207 \\
\hline$S O M$ & 0.222 & 0.012 & $\mathbf{0 . 8 4 6}$ \\
\hline$p H$ & 0.172 & -0.187 & $\mathbf{- 0 . 8 7 7}$ \\
\hline
\end{tabular}

In our present study, heavy metals show the following groups: [Co-Ni-Mn] $-[(\mathrm{Cu}-$ $\mathrm{Pb}-\mathrm{SOM})$ - $(\mathrm{Cd}-\mathrm{Zn}-\mathrm{Cr}-\mathrm{pH})] . \mathrm{Cu}$ and $\mathrm{Pb}$ accumulate in soil as in organic compounds, while $\mathrm{Cd}, \mathrm{Zn}$ and $\mathrm{Cr}$ accumulate due to soil neutralization [27].

\section{CONCLUSIONS}

In this work are shown some investigation results of pseudo total content of heavy metals in Ulaanbaatar surface soil.

Soil in Ulaanbaatar, especially in the central part of the city is highly distributed and itheir properties have changed due to urbanization and human activities.

The distribution pattern of pseudo-total content of heavy elements in the urban soil is uniform. Not showing the accumulation tendency for all investigated heavy metals.

The accumulation of heavy metals in Ulaanbaatar surface soil depends on the soil biogeochemical feature: organic matter for $\mathrm{Cu}$ and $\mathrm{Pb}$, alkaline for $\mathrm{Cd}, \mathrm{Zn}$ and $\mathrm{Cr}$ and soil parent material for $\mathrm{Co}, \mathrm{Ni}$ and $\mathrm{Mn}$.

Acknowledgments: This work was supported by the Mongolian Foundation for Science Technology through the Ministry of Education, Science, Culture and Sports of Mongolia under the project “№ SSA 2017/57 “(2017-2019). 


\section{REFERENCES}

1. Alloway, B. (2010). Heavy metals in soils: Trace metals and metalloids in soils and their bioavailability (3rd ed.). Berlin: Springer.

2. Kabata-Pendias A, Pendias H. Trace elements in soils and plants 2nd edition. Boca Raton, Florida CRC Press, 1992.

3. S. Tokalioglu, S. Kartal, and V. Yilmaz. An Assessment of Metal Sources by Multivariate Analysis and Speciation of Metals in Soil Samples Using the BCR Sequential Extraction Procedure. Clean Soil Air Water, 2010, 38(8), 713-18.

4. Rao C., Sahuquillo A., Lopez Sanchez J. A Review of the Different Methods Applied in Environmental Geochemistry for Single and Sequential Extraction of Trace Elements in Soils and Related Materials. Water Air Soil Pollution, 2008, 189 (1-4), 291-333.

5. Pfeiffer,E. M., Freytag, J., Scharpenseel, H. W. Investigation of heavy metal and arsenic pollution of soils and plants in the urban areas of Manila, Philippines. Mitteilungen der Deutschen Bodenkundlichen Gesellschaft. 1991, 66, 1169-1172.

6. Byambasuren Ts., Shabanova E. V., Korolkov A. T., Vasilyeva I. E., Ochirbat G., Khuukhenkhuu B. Distribution of Trace Elements in Soils of Ulaanbaatar. The Bulletin of Irkutsk State University. Series Earth Sciences, 2018, vol. 26, pp. 31-45. https://doi. org/10.26516/2073-3402.2018.26.31. (in Russian).

7. Byambasuren Ts., Shabanova E. V., Vasilyeva I. E., Korolkov A. T., Ochirbat G., Khuukhenkhuu B. Ecological description of Ulaanbaatar soil using methods of multivariate statistical analysis. Collection of Mineralogy and geochemistry of landscape of mountainore territories. The rational nature management. Modern mineral formation: Works of the 7th All-Russian symposium with international participation and works of the 14th All-Russian Readings devoted to academician A. E. Fersman, 22-25 August 2018, Chita, Russia. pp. 122-128. (in Russian).

8. Byambasuren Ts., E. V. Shabanova, I. E. Vasilyeva, A. T. Korolkov, Ochirbat G., Enkhzul B., Tsedenbaljir D., Khuukhenkhuu B. "Identification of technogenic and anthropogenic sources of trace elements in Ulaanbaatar soils." Book of Abstracts GMIT Symposium on Environmental Science and Engineering GMIT Nalaikh. 31 August - 2 September 2018. p. 34.

9. Ts. Byambasuren, B. Khuukhenkhuu, Shabanova E. V., Vasilyva I. E., G. Ochirbat, D. Tsedenbaljir. (2017). Application of some assessment approaches to study of Ulaanbaatar surface soil pollution with heavy metals. Proceedings of the Mongolian Academy of Sciences, 57(221), 18-28. https://doi.org/10.5564/pmas.v57i. 221.749.

10. Ts. Byambasuren, B. Khuukhenkhuu, E. V. Shabanova, I. E. Vasilyeva, B. Enhkzul. (2017). Some results of investigation of mobile forms of heavy metals in Ulaanbaatar soil. Proceedings of the Mongolian Academy of Sciences. 57, 3 (Oct. 2017), 21-36. DOI: https:// doi.org/10.5564/pmas.v57i3.886.

11. Byambasuren Ts., Shabanova E. V., Vasilyeva I. E., Khuukhenkhuu B., Tsedenbaljir D. "Enrichment factor of some heavy metal in Ulaanbaatar surface soil", Fourth International Scientific and Practical Conference - Soil as interlink for functioning of natural and anthropogenically transformed ecosystems, Irkutsk-Russia, 6-10 September 2016, pp. 344349.

12. Ts. Byambasuren, E. V. Shabanova, I. E. Vasilyeva, G. Ochirbat, D. Tsedenbaljir, B. Khuukhenkhuu1, B. Enkhzul, "The association of trace elements in Ulaanbaatar surface 
soil and their spatial distribution." Eleventh international conference "Sustainable natural resources and development in Mongolian plateau", Ulaanbaatar-Mongolia, 8-9 August 2016, p. 8.

13. Ts. Byambasuren, Ts. Otgontuul, Shabanova E. V., Vasilyeva I. E., Proydakova O. A., Khuukhtnkhuu B. Multivariate statistical approaches to identify pollution sources of heavy metal in Ulaanbaatar soil. Environment, Ecology, Family and Urban Studies (IJEEEUS), 2014, 4(5). 27-34.

14. Vasilyeva I. E., Shabanova E. V., Doroshkov A. A., Proydakova O. A., Otgontuul Ts., Khuukhtnkhuu B., Byambasuren Ts. Distribution of toxic and essential elements in soils of Ulaanbaatar city. In: Environment and sustainable development in Mongolian plateau and surrounding regions. 2013. Vol.1. P.67-71. https://docs.google.com/ 